\title{
Engagement of Social Workers in Policy Practice in Tanzania: A Case of Dar es Salaam, Tanzania
}

\author{
William Manyama \\ Assistant lecturer, Institute of Social Work, Tanzania \\ Tel: 255-224-560. E-mail: williammanyama@yahoo.com
}

Abu Mvungi

Lecturer, Institute of Social Work, Tanzania

Tel: 255-713-234-446. E-mail: rector@isw.ac.tz

Received: December 2, 2017 Accepted: December 20, 2017 Published: December 22, 2017

doi:10.5296/ijsw.v5i1.12351 URL: http://doi.org/10.5296/ijsw.v5i1.12351

\begin{abstract}
Social workers are potential change agents who can be used to transform the lives of the vulnerable populations in the world and Tanzania, in particular. This is achieved through actively and creatively participating in policy formulation and change (policy advocacy and change, analysis, launching campaigns and building coalitions). The powers social workers have are derived from the professional legality vested in them in making practice decisions. By utilizing their powers, skills and knowledge as change agents, they can considerably imbue social policies with pro-poor approach that puts social justice at the centre of development. Drawing from the findings of a study conducted in Dar es Salaam, this paper shows that social workers' engagement in policy practice was low. The reasons ascribed to low policy practice engagement are lack of policy practice competencies/specialized training in policy practice, institutional/organizational interest/influence, lack of resources and fear. The paper shows that low engagement of policy practice has partly contributed to the low visibility, recognition of social work profession, practice and inefficient provision of welfare services in Tanzania. This article argues that it is very important for social workers to use their social policy skills and knowledge so as to bring positive social and economic outcomes to the lives of the vulnerable populations in Tanzania. This can be successfully done by using professional associations such as TASWO, establishing Social Work Council and forging cooperation with NGOs in advocating not only for policy implementation but also policy research and change.
\end{abstract}


Keywords: Social work, Policy practice, Engagement, Advocacy and research

\section{Introduction}

Policy practice has had a potentially significant influence on social work profession, both as a field of study and an area of practice. It is an essential component of social work as experienced in all settings i.e., at the micro, mezzo, and macro levels of intervention (Cummins, Byers, \& Pedrick, 2011). History is replete with evidence showing that policy practice paved the way for the development of social work profession as people used different social work skills to campaign for the formalization of the social work profession. The potential of policy practice became the cornerstone of social work profession which was established through principles that promote social justice and advocacy for marginalized individuals in the society (Cummins, Byers, \& Pedrick, 2011).

Historically, social workers have had a vigorous involvement at both the macro and micro levels of policy practice, thus creating a larger impact at different levels of the spectrum. However, in the last decades, the social work profession has witnessed a gradual shift towards case work level with little emphasis on policy practice. This situation is very evident in developing countries with vestiges of colonialism and globalization (Spitzer \& Twikirize, 2014). Policy practice for social workers is the use of social work skills to influence policy change in favour of powerless groups-women, children, poor people, people with disability. Our concern is therefore the way to which social workers have engaged themselves in this crucially important task in improving the well-being of the majority poor (Cummins, Byers, \& Pedrick, 2011).

Spitzer and Twikirize (2014), are of the view that vulnerable populations in East Africa are faced with a plethora of life challenges including: poverty and deprivation, gender inequality and gender based violence (GBV), Female genital mutilation (FGM), child trafficking and other forms of violence against children (VAC), HIV/AIDS and other diseases, and violation of human rights i.e., killing of people with albinism, stigma and discrimination against people with homosexual orientation. Spitzer and Twikirize (2014) pointed out that some of the factors that have contributed to these persistent challenges facing the vast majority of client population in East Africa are; first, the failure to bridge the gap between micro and macro social work practice. Therefore, social work practice should transcend this divide and use social work skills to address structural and institutional factors, and inform policies at all levels.

Second, the invisibility of social work profession has intensified/engendered the violation of human rights in East Africa. Healy (2008) and Ife (2001) argued that social work from its initial stage has been very much concerned with the protection of human rights and this has made the profession to be widely recognized as the human rights profession. Contrary to this expectation, in East Africa there is a widespread occurrence of human rights violation in the midst of social work profession. Spitzer and Twikirize (2014: 377) show this concern when they ask "Where are the social workers who raise their voice for human rights of these stigmatized and victimized groups?" Analogous situation of social work silence and passivity in Africa was reported by Edmos and Munyaradzi (2013) in Zimbabwe. They reported that social workers' roles were visibly left in the hands of other professionals i.e., lawyers, religious associations, medical doctors, journalists and teachers. Edmos and Munyaradzi 
(2013) and Mmatli (2008) assert that the reluctance of the social work profession to actively deal with burning social, economic and political issues distressing the society is translated as a denial of social work professional values.

There is no denial that the role of social workers in policy practice is very crucial, to ensure social and economic justice. However, there has been a dearth of empirical study of social workers' engagement in policy practice. This has impeded us from having a systematic knowledge of social workers' role as change agents in Tanzania. One of the few studies providing information on policy advocacy in Tanzania comes from Spitzer and Twikirize (2014), who highlighted the prevalence of many social problems facing East African countries i.e., poverty, gender based violence (GBV), child trafficking and violence against children (VAC), HIV/AIDS, in the midst of social work profession. Citing Mmatli (2008), Spitzer and Twikirize (2014) pointed out that most of the problems facing clients are linked to structural and political processes which need a strong engagement of social workers to up-root them. This piece of literature was limited to issues of advocacy and the results were too general. It is therefore important to explore how social workers use their skills to change/improve the policies and laws that affect the lives of their client populations through policy practice.

In other words much more contextual understandings of the status of policy practice in Tanzania are needed. Since the subject of policy practice is too broad, this paper focused on four dimensions of policy practice namely policy advocacy and change, building coalitions, launching campaign and policy research and analysis in grappling with social and economic problems facing people and communities in Tanzania.

It is also important to point out from the outset that we acknowledge the complexities of social and economic problems facing our societies in Tanzania i.e., poverty and deprivation, gender inequality and gender based violence (GBV), drug abuse, Female genital mutilation (FGM), child trafficking and other forms of violence against children (VAC), HIV/AIDS and other diseases and violation of human rights. Violation of human rights involves killing of people with albinism. These issues require a combination of multiple strategies to avert them, including policy practice. This underscores the need to gaining an understanding on how social workers engage in policy practice in Tanzania to gauge the response of social work to the vulnerable populations of Tanzania. This paper is an attempt to contribute some evidence-based knowledge that may be used to inform the social work professionals in their attempt to realize a society that is free from social and economic injustice.

\section{Data and Materials}

Information for this paper is based on a qualitative study which had the objective of generating in-depth information on the experiences of social work professionals and practitioners in their endeavor to provide services and their involvement in policy change, formulation and implementation. In this regard, in-depth interview and focus group discussions (FGDs) were employed in qualitative approach to deploy complexity of the reality (Mason, 2003). A total number of 16 people participated in this study through in-depth interviews and FGDs. Further, the study adopted a case study research design. Case study was chosen because of its capacity in generating holistic information (Cresswell, 2009). Dar es Salaam was purposely selected as the study area as it was then the Government 


\section{Macrothink}

Headquarters with social workers working at the Headquarters of the Social Welfare Department (DSW) and has the largest share of social service agencies in the country.

Data were collected using purposive and snowball non-probability sampling techniques. In analyzing the data, this study used the thematic analysis method. The study compared and contrasted each and every element of data, finding sequence and patterns to understand their relationships with the problem at hand (Vartanian, 2011). Official permission (ethical clearance) to conduct the research was sought from the Institute of Social Work and presented to the study area. All other ethical standards (informed consent, confidentiality, objectivity in reporting, ethical publishing practices etc) were adhered to, before, during and after the execution of the study.

\section{The Findings}

This section presents and discusses the findings of the study. This section falls into four sub-sections which are policy advocacy and change, launching campaigns, building coalitions, policy research.

\subsection{Policy Advocacy and Change}

According to the findings, social workers depicted mixed views with regard to their engagement in policy advocacy. Some accepted that they had been engaged in policy advocacy, some said "No", and some said they had not fully engaged themselves in policy advocacy. However, all of the informants agreed that at least they engaged themselves in advocating for policy implementation and much less effort was being invested in policy formulation and change at different levels of practice. One of the informants, representing those who said that they had been engaged in policy advocacy at the level of implementation had the following captured the activity mostly performed by social workers when she said that

Yes...we are reminding the local government authority or council, during the meetings to set aside a budget for implementing social policies (Female informant, 43 years, Government employee)

Another informant was more elaborate as to what social workers do as part of policy advocacy; At my work place, I have been advocating for implementation of different policies like disability policy, child development policy and health policy...we create awareness to the council members on how important is to provide relevant services to the vulnerable populations like the elderly, children and disabled (Male social worker, 38 years, Government employee)

Other informants said that they were simply participating in implementing policies while providing the services and hence very little had been, and was being invested in policy advocacy:

I would like to be honest, most of us are translating the policies into actions...we are serving people from the very morning and hence very little we can do on policy advocacy. The reason is that my job description is silent about that (Female social worker, 37 years, Government employee)

Another informant who had similar views said:

Participating fully in policy advocacy requires a supportive working environment. We are overwhelmed with clients who mostly have matrimonial conflicts and affiliation cases. This is 


\section{Ml Macrothink}

what I found people doing since I was employed here... We are not empowered to deal with policy issues.... (Female social worker, 41 years, Government employee)

In line with the above the non participation of social workers in policy advocacy was attributed to a claim that they seemed not to be well versed with the various policies. In the absence of such capacity it was impossible for them to engage in policy advocacy. The foregoing is well illustrated by a quote from an informant from the in-depth discussion who said:

We have to be frank; social workers are not reading policies. How can you properly advocate for a policy which you do not know? People are providing services as business as usual. I think the government has to know that there is a problem, may be people are frustrated by the working environment. Second, as a frustrated person, how can you advocate for social policies while you are also not satisfied with the working conditions? (Female social worker, 39 years, Government employee).

Contrary to above, NGOs informants indicated to participate in policy advocacy for change and this was done mainly through media, outreach programs, publication of research reports. An informant from an NGO in an in-depth interview had this to say:

Yes, we are very much engaged in policy advocacy. There are different ways to do this, like media programmes, outreach programmes... (Female social worker, 41 years, NGO employee).

And again showing the activities that they perform as people who do policy advocacy, another informant had this to say:

We are trying to raise awareness in the society, by using diverse techniques including media advocacy. For example, some of the issues we have been advocating include implementation of Sexual Offence Special Provisions Act of 1998, the law of the child act of 2009 (Female social worker, 36 years, NGO employee).

The researchers were interested to know, the strategies used by social workers to advocate for social policy implementation. It was found that they mostly rely on public celebrations events. A quote from an informant is illustrative of the foregoing:

Our organization invites key government officials at different functions like when celebrating world women day, world elderly people day etc. we are also mobilize workshops, seminars and symposiums. We also do media advocacy and campaigns (Female social worker, 44 years, NGO employee).

The analysis shows that most of the social work practitioners employed by the government are not dealing with policy advocacy directly. They simply use policies as their guidelines when providing the services while social workers employed by NGOs are closely involved in policy advocacy with the exception of civil society organizations, which have demonstrated an inspiring capacity and actively involved in advocating for policy formulation, implementation and change. Since policy practice for social workers is the use of social work skills and knowledge to influence policy formulation and change, its absence means that social policies in Tanzania lack the important input of social workers. It is no wonder that the invisibility of social work in Tanzania is bemoaned.

As argued earlier, the importance of policy practice in addressing social and economic problems in Tanzania cannot be overemphasized. An outcry with regard to the invisibility of 
policy practice was also shared by Spitzer and Twikirize (2014), who related the existing social problems in East Africa to the failure to bridge the gap between micro and macro social work practice. Therefore, social work practice should transcend this divide and use social work skills and knowledge to address structural and institutional factors, and inform policies at all levels. Such an approach is very crucial for poor countries like Tanzania where the struggle is on for inclusive and holistic development. In addition to that, Sansa (2012) argues that the tendency of social workers to provide welfare/solving social problems based on individuals needs, as their daily routine in Tanzania, accounts for the widening gaps between micro and macro levels of policy practice which involve policy issues. Second, the silence of social workers has certainly engendered the violation of human rights in East Africa. Healy (2008) and Ife (2001) argued that this is contrary to the initial mission of social work profession stage, which were centered on the protection of human rights.

Using the social work experience in Zimbabwe, Edmos and Munyaradzi (2013), remarked that social workers' roles were visibly left in the hands of other professionals i.e., lawyers, religious associations, medical doctors, journalists and teachers. Edmos and Munyaradzi (2013) Mmatli (2008), Heinonen \& Spearman, (2001) further assert that the reluctance of the social work profession to actively engage in policy issues, in order to address social, economic and political issues distressing the society is translated as a denial of social work professional values.

\subsection{Building Coalition}

The findings indicate that social workers are doing well in this aspect. The study informants pointed out that they were collaborating well with different organizations with the purpose of enhancing service provision. In addition, networking among organizations and individuals has been established to solve problems facing clientele and community. Informants had the following to say

We are working closely with other NGOs because we cannot do everything on our own. Sometimes we refer cases to other social service agencies. (Male social worker, 34 years, Government employee)

Networking is one of the key components of social work practice, so we are cooperating with other actors in order to provide better services... (Female employee, 36 years, NGO employee)

The analysis shows that most of the social workers are using networking as one of the ways of ensuring smooth provision of welfare services. However, the said net-workings are rarely geared towards collaborating with other NGOs to change existing social policies that are found to be inadequate in terms of improving the welfare of the poor, voiceless and vulnerable. This reflects the above observation that social workers engagement in policy practice is low. Spitzer and Twikirize (2014) convincingly argue that social workers, through their associations, in East Africa have the potential opportunities of collaborating with civil society organizations to influence change. Social workers have to network one another, engage in debates and different forums that eventually come up with some resolutions and action points that will create awareness to authorities for appropriate resource allocations to finance social work practice (Midgley \& Conley 2010).

\subsection{Launching Campaigns}




\section{Ml Macrothink}

International Journal of Social Work

ISSN 2332-7278

2018, Vol. 5, No. 1

The findings have depicted that social workers do differ in terms of participating in policy campaigns. Those employed by the government were not significantly supportive to policy campaigns while those employed by NGOs were found to be very supportive of this approach in order to realize that the policies are implemented. Some of the social workers said that, as direct social workers, were not aware of this role.

One of the social workers working in an NGO said:

We have been launching campaigns at different levels. Our NGO is mostly engaged in media campaigns... and occasionally we have been doing outreach programmes... (Female social worker, 42 years, NGO employee)

Other social workers were skeptical with this approach, saying that as a government employee it is difficult to campaign for policy change. During the FGDs, in Dar es Salaam, one of the informants had the following to say:

As far as I know, as a government employee, it is difficult to participate in campaigns....they will say that you are belonging to the opposition parties... (Female employee, 37 years, Government employee)

Another informant supported this, by saying:

Being active in campaigns for change translates that one is against the government...in the local government authority we are limited by regulations. That is why you see TASWO is not responding immediately to different social injustice in the society. This is because most of the leaders are government employees and hence they fear to build arguments and pointing fingers to the government....(Male social worker, 45 years, Government employee)

Some of the participants said that they are constrained with organization structures. One of the informants had the following to say:

Launching campaigns against something is difficult, unless we use our associations like TASWO.... you cannot launch it from the government office (Female informant, 32 years, NGO employee)

Analysis shows that most of the social workers employed by the government cannot participate fully in launching campaigns against prevailing social and economic injustice because they are afraid of being labeled as rebels. What is reflected here again is weakness in organization of the profession. This is because if the social workers galvanize their support towards implementation of the poverty eradication strategy, the ruling party manifesto, Vision 2025 and the second Five Year Development Plan can achieve a lot in terms of changing the prevailing political and economic injustice. Further, Spitzer and Twikirize (2014) pointed out that social workers engagement in political activism account for the cornerstone of social work practice. However, given the oppressive political atmosphere, politically motivated violence from the state apparatus and undemocratic decisions and corruption facing some of the East African countries, social and economic justice campaigns can be done in collaboration with civil society and grassroots organizations which are dealing with social welfare services.

\subsection{Policy Analysis and Research}

Policy analysis and research are central if one was to come up with policies that capture the real situation on the ground. Policy that is not anchored on research is as good as no policy. For a policy to change a given situation it must correctly depict it. Our findings show a very 
different situation in Tanzania. That it is the most neglected part of policy practice in Tanzania. Most policies tended to miss out in terms of empirical evidence as at times they heavily borrow or generalize instead of ensuring that the context of the problem with its dynamics is captured. Social workers who were interviewed, working as direct practice social workers said that very little had been done in this aspect, with the exception of a few social workers, working at the macro level.

Policy analysis is not done...I have to be honest. Before joining the masters' degree programme, I had no any idea about this.... (Female social worker, 42 years, Government employee)

Another informant said:

There should be a favorable environment for policy analysis and evaluation... as social workers we have experiences because we are providing services every day. So, we need to be empowered to know how to analyze policies...we should be provided with in-service training. Otherwise, it is difficult (Male social worker, 38 years, Government employee)

According to what I know policy analysis and research is mostly done by NGOs like UNICEF and IRC, TAMWA. But it is a big challenge for social workers employed by the government because there are issues of resources... (Female social worker, 40 years, Government employee)

With regard to the policy research, one of the informants had the following to say:

In my council there is not budget for policy research... a huge amount of money is located to health sector. Very little consideration is given to social welfare services... (Female employee, 38 years, Government employee)

Another informant, working in a civil society organization had the following to say:

We are conducting research to gauge the extent/severity of the problems and research on existing policies/laws which perpetuate violation of women and children rights (Female social worker, 36 years, NGO employee)

The analysis shows that policy issues have not been given due attention among the social workers employed by the Government. It is thus sensible to conclude that there is a serious problem in terms of social policy research in Tanzania. According to Walker \& Walker (2002) social policy research provides the context within which both social work professionals and their service users live and work. Social workers, therefore, need to engage in research on and policy analysis to grasp and identify gaps in social policies with a view of participating effectively in policy formulation, implementation and change. Engaging in research give the social workers power to successfully argue for change of policy and it is only with evidence base policy that one can hope to achieve an effective implementation (Walker \& Walker, 2002)

\section{Conclusion}

The study findings have clearly shown that engagement of social workers in policy practice in Tanzania is very low. This is evident especially for social workers employed by the Government. Some of the reasons attributed to this, according to the findings were related to organizational/institutional, individual and lack of specialized training in policy practice. The low engagement of social workers in policy practice translates that the vulnerable populations 
are missing the quality services. Brechin (2000) also argues that it is important for social workers to understand the policy context surrounding various social, economic and political problems facing their societies and evaluate the extent to which those policies act as enablers and constraints to social change, and eventually formulate new ones, or improve and change the existing ones.

\section{Recommendations}

First, since most of the problems confronting social workers seem to be associated with organizational/institutional/structural factors, social workers have to capitalize on the social workers association known as TASWO in order to achieve social and economic justice. This association has to be strengthened so that it can clearly represent the interest of social workers, profession and clients. Moreover, the process to revitalize TASWO has to go concurrently with the formation of Social Work Council in Tanzania. The advantage of such association and Council is that it will be able to focus and coordinate efforts of all social workers towards performing their crucial role of advocacy.

Haaland, Njå and Montgomery (1999) remind social workers that they have been given a mandate by the society to take decisions that have an impact on the lives of those who need help. Thus, social workers are expected to sense the problems of the society more keenly than people in other professions. They meet users who reflect the society's problems, and represent a link between the individual user or group of users and the environment with various policies/institutions. Social workers could be messengers who keep institutions and politicians informed of the situation in society and offer solutions for improvements. This can be done through professional associations.

Second, while we acknowledge statutory duties, we wish to emphasize that, social workers have also to engage themselves in policy advocacy and change, policy analysis, policy research and collaborating with other stakeholders in order to attain social and economic fairness (see also Adams, 2002; Sansa, 2012). Such engagement will help imbue the change process with social work thinking, practice and perspective and improve on the uptake of social work interventions. Further, the relationship between social work and social policy has been termed a point of integration or tangent by several authors (Reamer 1993; Fjortoft \& Skorstad 1998; Kokkinn 1998; Villadsen, Gruber \& Bengtsson 1998; Hegland 2000). Thus, no social worker can avoid drawing a connection between users' needs and publicly sponsored programs, regulations, or benefits.

Third, more resources need to be allocated to promote policy practice and integrate macro and micro levels in social work programs. Increasing policy practice classes in the social work curricula, hiring more policy expert staff, adopting a more generalist view, and increasing awareness of its value and relevance to create social change can all be starting points to a more balanced policy practice in Tanzania.

\section{Acknowledgement}

First and foremost, we would like to say that this work would not have been possible without support and research permit from the Institute of Social Work. We would also like to thank our informants who, despite having much to do as Government and NGOs employees, they spared their time to participate in this study. God bless you all! 


\section{References}

Adams, R. (2002). Social Policy for Social Work. Basingstoke: Palgrave. https://doi.org/10.1007/978-0-230-80178-3

Alcock, P. et al. Ed. (2003). The Student Companion to Social Policy. Oxford, Blackwell Publishers.

Aquino, G. G., Flores, N., Torres, D., \& Kien, S. (2017). The Value of Social Policy Practice for Social Work Professionals. Retrieved from http://www.socialworker.com/extras/social-work-month-2017/the-value-of-social-policy-prac tice-for-social-work-professionals

Bardach, E. (2009). A Practical Guide for Policy Analysis: The Eightfold Path to More Effective Problem Solving. New York, NY: Chatham House Publishers.

Barush, A. (2012). Foundations of Social Policy; Social Justice in Human Perspective. Belmont, Brooks/Cole.

Brechin, A. (2000). Introducing critical practice. In A. Brechin, H. Brown, \& M. Eby (Eds.), Critical practice in health and social care (pp. 25-47). London: Open University Press.

Lavalette, M., \& Pratt, A. (2006). Social Policy: Theories, Concepts and Issues. (3rd Ed). London and New Delhi: Thousand Oaks.

Clasen, J. Ed. (1999). Comparative Social Policy: Concepts, Theories and Methods. Blackwell Publishers, Oxford.

Cummins, K, L., Byers, V. K., \& Pedrick, L. (2011). Policy practice for social workers: New Strategies for a new era (updated edition). Boston, MA: Allyn \& Bacon.

Edmos, M., \& Munyaradzi, M. (2013). The price of professional silence: social work and human rights in Zimbabwe. AJSW, 3(1).

Ife, J. (2001). Human rights and social work: Towards rights-based practice. Cambridge: University Press. https://doi.org/10.1017/CBO9781139164689

International Federation of Social Workers [IFSW]. (2000). Definition of social work. Retrieved from http://www.ifsw.org/p38000279.html

Healy, L. (2008). Exploring the history of social work as a human rights profession. International Social Work, 51(6), 735-748. https://doi.org/10.1177/0020872808095247

Jansson, B. (2008). Becoming an Effective Policy Advocate: From Policy Practice to Social Justice, (5th Ed). Belmont: Thomson Brooks/Cole.

Jansson, B. S.; Dempsey, D., McCroskey, J., \& Schneider, R. (2005). Four Models of Policy Practice: Local, State and national Arenas. In M. Weil (Ed) The Handbook of Community Practice (pp. 319-337). London: Sage. https://doi.org/10.4135/9781452220819.n17

Rocha, C. (2007). Essentials of Social Work Policy Practice. Hoboken, NJ: Wiley \& Sons.

Wells, C. C., \& Suppes, M. A. (2000). The Social Work Experience: An Introduction to Social Work and Social Welfare. Third edition, Mc Graw - Hill, Inc., New York

Sansa, G. (2012). Developing social policy training and research capacity for social workers and professionals in Tanzania. A paper presented at the Institute of Social Work at Social Work Forum. 


\section{Macrothink}

International Journal of Social Work

ISSN 2332-7278 2018, Vol. 5, No. 1

Spitzer, H., \& Twikirize, J. (2014). A vision for Social Work in East Africa. Professional social work in east Africa: Towards social development, poverty reduction and gender equality (pp. 232-244). Kampala, Fountain publishers.

Spicker, P. (2014). Social Policy: Theory and Practice (3rd edition) Chicago. University of Chicago Press. https://doi.org/10.2307/j.ctt1t89dgr.26

Wells, C. C., \& Suppes, M. A. (2000). The Social Work Experience: An Introduction to Social Work and Social Welfare. Third edition, Mc Graw - Hill, Inc., New York

\section{Copyright Disclaimer}

Copyright reserved by the author(s).

This article is an open-access article distributed under the terms and conditions of the Creative Commons Attribution license (http://creativecommons.org/licenses/by/3.0/). 